\title{
THE GROWTH MODEL OF THE NUMBER OF INNOVATIVELY ORIENTED FIRMS AND THE SPATIAL DIFFUSION OF INNOVATIONS
}

\author{
Andrey Zhuravka \\ Department of Economic Cybernetics and Information Technologies \\ Kharkiv National University of Construction and Architecture \\ 40 Sumskaya str., Kharkiv, Ukraine, 61000 \\ andy_zhuravka@mail.ru \\ Mudashiru Tayo Musibau \\ Department of Economic Cybernetics and Management of Economic Security \\ Kharkiv National University of Radio Electronics \\ 14 Nauki ave., Kharkiv, Ukraine, 61166
}

\begin{abstract}
In conditions of transition of Ukraine to the model of innovative development, the transition from the mathematical models with lumped parameters to mathematical models with distributed parameters will be of great importance. This follows from the fact that technopolis can be represented in the form of regional innovation systems with distributed parameters (characteristics). Such system may include technology parks, scientific parks, innovation funds, venture and consulting firms, higher education institutions, business schools, service infrastructure servicing, etc.

Keywords: model of innovative development, number of innovatively oriented firms, spatial diffusion of innovations, technology parks, scientific parks, innovation funds, venture and consulting firms, higher education institutions, business schools serving the service infrastructure.
\end{abstract}

\section{Introduction}

Let's consider an autonomous third-order dynamic system describing the dynamics of firms of producers $(\mathrm{G})$, distributors $(\mathrm{N})$ and consumers $(\mathrm{P})$ of innovations. The initial equations within the framework of the considered concept have the form:

$$
\frac{\mathrm{dG}}{\mathrm{dt}}=(\alpha-\beta) \mathrm{G}, \frac{\mathrm{dN}}{\mathrm{dt}}=(\tilde{\alpha}-\tilde{\beta}) \mathrm{N}, \frac{\mathrm{dP}}{\mathrm{dt}}=(\bar{\alpha}-\bar{\beta}) \mathrm{P} .
$$

When specifying the factors of birth and death of firms in the form of linear additive functions:

$$
\begin{cases}\alpha=\alpha_{0}+\gamma_{12} \mathrm{~N}+\gamma_{13} \mathrm{P}, & \beta=\beta_{0}+\beta_{1} \mathrm{G}, \\ \tilde{\alpha}=\tilde{\alpha}_{0}+\gamma_{21} \mathrm{G}+\gamma_{23} \mathrm{P}, & \tilde{\beta}=\tilde{\beta}_{0}+\tilde{\beta}_{1} \mathrm{~N}, \\ \bar{\alpha}=\bar{\alpha}_{0}+\gamma_{31} \mathrm{G}+\gamma_{32} \mathrm{~N}, & \bar{\beta}=\bar{\beta}_{0}+\bar{\beta}_{1} \mathrm{P} .\end{cases}
$$

In [1] the following three-dimensional dynamical system is proposed:

$$
\left\{\begin{array}{l}
\frac{\mathrm{dG}}{\mathrm{dt}}=\left[\left(\alpha_{0}-\beta_{0}\right)-\beta_{1} \mathrm{G}\right] \mathrm{G}+\gamma_{12} \mathrm{GN}+\gamma_{13} \mathrm{GP}, \\
\frac{\mathrm{dN}}{\mathrm{dt}}=\left[\left(\tilde{\alpha}_{0}-\tilde{\beta}_{0}\right)-\tilde{\beta}_{1} \mathrm{~N}\right] \mathrm{N}+\gamma_{21} \mathrm{NG}+\gamma_{23} \mathrm{NP}, \\
\frac{\mathrm{dP}}{\mathrm{dt}}=\left[\left(\bar{\alpha}_{0}-\bar{\beta}_{0}\right)-\bar{\beta}_{1} \mathrm{P}\right] \mathrm{P}+\gamma_{31} \mathrm{PG}+\gamma_{32} \mathrm{PN},
\end{array}\right.
$$

which is a model of pairwise cooperative interactions. 
Let's show that the dynamical system (3) has eight singular points, as is done in [1], if

$$
\mathrm{K}=\beta_{1}\left(\gamma_{23} \gamma_{32}-\tilde{\beta}_{1} \bar{\beta}_{1}\right)+\gamma_{12}\left(\bar{\beta}_{1} \gamma_{21}+\gamma_{31} \gamma_{23}\right)+\gamma_{13}\left(\tilde{\beta}_{1} \gamma_{31}+\gamma_{21} \gamma_{32}\right)
$$

then it is assumed that the initial birth rates of different types of firms are more than the initial rates of their death, so if

$$
\alpha_{0}-\beta_{0}>0, \quad \tilde{\alpha}_{0}-\tilde{\beta}_{0}>0, \quad \bar{\alpha}_{0}-\bar{\beta}_{0}>0
$$

that point 1 is an unstable node, and points $2-4$ are saddles. Thus, there are no stable equilibrium states of the dynamical system (3) with the disappearance ("extinction") of two or three kinds of firms. Let's write all the singular points:

1. $\mathrm{G}^{*}=\mathrm{N}^{*}=\mathrm{P}^{*}=0 ; \quad 2 . \mathrm{G}^{*}=\mathrm{N}^{*}=0, \mathrm{P}^{*}=\frac{\bar{\alpha}_{0}-\bar{\beta}_{0}}{\beta_{1}}$

3. $\mathrm{G}^{*}=\mathrm{P}^{*}=0, \quad \mathrm{~N}^{*}=\frac{\tilde{\alpha}_{0}-\tilde{\beta}_{0}}{\tilde{\beta}_{1}} ; \quad 4 . \mathrm{G}^{*}=\frac{\alpha_{0}-\beta_{0}}{\beta_{1}}, \mathrm{~N}^{*}=\mathrm{P}^{*}=0$;

5. $\quad \mathrm{G}^{*}=0, \quad \mathrm{~N}^{*}=\frac{\left(\tilde{\alpha}_{0}-\tilde{\beta}_{0}\right) \bar{\beta}_{1}+\left(\bar{\alpha}_{0}-\bar{\beta}_{0}\right) \gamma_{23}}{\tilde{\beta}_{1} \bar{\beta}_{1}-\gamma_{23} \gamma_{32}}, \quad \mathrm{P}^{*}=\frac{\left(\tilde{\alpha}_{0}-\tilde{\beta}_{0}\right) \gamma_{32}+\left(\bar{\alpha}_{0}-\bar{\beta}_{0}\right) \tilde{\beta}_{1}}{\tilde{\beta}_{1} \bar{\beta}_{1}-\gamma_{23} \gamma_{32}} ;$

6. $\quad \mathrm{G}^{*}=\frac{\left(\alpha_{0}-\beta_{0}\right) \bar{\beta}_{1}+\left(\bar{\alpha}_{0}-\bar{\beta}_{0}\right) \gamma_{13}}{\beta_{1} \bar{\beta}_{1}-\gamma_{13} \gamma_{31}}, \quad \mathrm{~N}^{*}=0, \quad \mathrm{P}^{*}=\frac{\left(\alpha_{0}-\beta_{0}\right) \gamma_{31}+\left(\bar{\alpha}_{0}-\bar{\beta}_{0}\right) \beta_{1}}{\tilde{\beta}_{1} \beta_{1}-\gamma_{13} \gamma_{31}}$

7. $\mathrm{G}^{*}=\frac{\left(\alpha_{0}-\beta_{0}\right) \tilde{\beta}_{1}+\left(\tilde{\alpha}_{0}-\tilde{\beta}_{0}\right) \gamma_{12}}{\tilde{\beta}_{1} \beta_{1}-\gamma_{12} \gamma_{21}}, \mathrm{~N}^{*}=\frac{\left(\alpha_{0}-\beta_{0}\right) \gamma_{21}+\left(\tilde{\alpha}_{0}-\tilde{\beta}_{0}\right) \beta_{1}}{\tilde{\beta}_{1} \beta_{1}-\gamma_{12} \gamma_{21}}, \mathrm{P}^{*}=0$;

8. $\quad G^{*}=\left[\left(\alpha_{0}-\beta_{0}\right)\left(\gamma_{23} \gamma_{32}-\tilde{\beta}_{1} \bar{\beta}_{1}\right)-\left(\tilde{\alpha}_{0}-\tilde{\beta}_{0}\right)\left(\bar{\beta}_{1} \gamma_{12}+\gamma_{13} \gamma_{32}\right)-\left(\bar{\alpha}_{0}-\bar{\beta}_{0}\right)\left(\tilde{\beta}_{1} \gamma_{13}+\gamma_{12} \gamma_{23}\right)\right] / \mathrm{K}$, $\mathrm{N}^{*}=\left[-\left(\alpha_{0}-\beta_{0}\right)\left(\tilde{\beta}_{1} \gamma_{21}+\gamma_{23} \gamma_{31}\right)-\left(\tilde{\alpha}_{0}-\tilde{\beta}_{0}\right)\left(\beta_{1} \bar{\beta}_{1}-\gamma_{13} \gamma_{31}\right)-\left(\bar{\alpha}_{0}-\bar{\beta}_{0}\right)\left(\beta_{1} \gamma_{23}+\gamma_{13} \gamma_{21}\right)\right] / \mathrm{K}$, $\mathrm{P}^{*}=\left[-\left(\alpha_{0}-\beta_{0}\right)\left(\tilde{\beta}_{1} \gamma_{31}+\gamma_{21} \gamma_{32}\right)-\left(\tilde{\alpha}_{0}-\tilde{\beta}_{0}\right)\left(\beta_{1} \gamma_{32}+\gamma_{12} \gamma_{31}\right)-\left(\bar{\alpha}_{0}-\bar{\beta}_{0}\right)\left(\beta_{1} \tilde{\beta}_{1}-\gamma_{12} \gamma_{21}\right)\right] / \mathrm{K}$,

A similar situation occurs in the cases $5-7$, and then we have

$$
\begin{aligned}
& \tilde{\alpha}_{0}-\tilde{\beta}_{0}=\bar{\alpha}_{0}-\bar{\beta}_{0}, \tilde{\beta}_{1}=\bar{\beta}_{1}, \gamma_{23}=\gamma_{32}, N^{*}=\mathrm{P}^{*}=\frac{\tilde{\alpha}_{0}-\tilde{\beta}_{0}}{\tilde{\beta}_{1}-\gamma_{23}} \text { (point 5); } \\
& \alpha_{0}-\beta_{0}=\bar{\alpha}_{0}-\bar{\beta}_{0}, \beta_{1}=\bar{\beta}_{1}, \gamma_{13}=\gamma_{31}, G^{*}=\mathrm{P}^{*}=\frac{\alpha_{0}-\beta_{0}}{\beta_{1}-\gamma_{13}} \text { (point 6); } \\
& \alpha_{0}-\beta_{0}=\tilde{\alpha}_{0}-\tilde{\beta}_{0}, \quad \beta_{1}=\tilde{\beta}_{1,} \gamma_{12}=\gamma_{21}, G^{*}=\mathrm{N}^{*}=\frac{\alpha_{0}-\beta_{0}}{\beta_{1}-\gamma_{12}} \text { (point 7). }
\end{aligned}
$$

The case of the eighth singular point can be considered when

$$
\alpha_{0}-\beta_{0}=\tilde{\alpha}_{0}-\tilde{\beta}_{0}=\bar{\alpha}_{0}-\bar{\beta}=\alpha^{*},
$$

then its coordinates take the form: 


$$
\mathrm{G}^{*}=\mathrm{N}^{*}=\mathrm{P}^{*}=\frac{-\alpha^{*}\left(\beta^{*}+\gamma\right)^{2}}{2 \gamma^{3}+3 \beta^{*} \gamma^{2}-\left(\beta^{*}\right)^{3}}
$$

This expression will be positive when $2 \gamma^{3}+3 \beta^{*} \gamma^{2}-(\beta *)^{3}<0$.

Substituting in this inequality $\gamma=\mathrm{n} \beta$, where $\mathrm{n}-$ a positive real number, let's obtain the inequality $0<\mathrm{n}<\frac{1}{2}$. Thus, in the interval $0<\gamma<\frac{\beta^{*}}{2}$ the coordinates of the eighth considered singular point are positive.

The Jacobi matrix for the system (3) at the considered singular point $\mathrm{G}^{*}=\mathrm{N}^{*}=\mathrm{P}^{*}=\mathrm{X}^{*}$ has the form:

$$
A=\left[\begin{array}{ccr}
-\beta * X^{*} & \gamma X^{*} & \gamma X^{*} \\
\gamma X^{*} & -\beta * X^{*} & \gamma X^{*} \\
\gamma X^{*} & \gamma X^{*} & -\beta * X^{*}
\end{array}\right]
$$

The corresponding characteristic equation can be obtained in the form:

$$
\left[\left(\beta^{*}+\gamma\right) X^{*}+\lambda\right]\left[\left(\beta * X^{*}+\lambda\right)\left(-\beta * X^{*}+\gamma X^{*}-\lambda\right)+2 \gamma^{2}\left(X^{*}\right)^{2}\right]=0,
$$

which has the following roots:

$$
\lambda_{1,2}=-X^{*}\left(\beta^{*}+\gamma\right)<0, \quad \lambda_{3}=X^{*}\left(2 \gamma-\beta^{*}\right)<0 .
$$

Thus, in the particular case $\left(0<\gamma<\frac{\beta^{*}}{2}\right)$ we obtain a stable node. It can be shown that obtained local stability at a non-trivial point is global.

Let's give several calculations of stable equilibrium states (4) for really possible values of the model parameters. Thus, for obtained $=50$ year ${ }^{-1}, \beta^{*}=4$ (year $\times$ firm $)^{-1}, \gamma=1$ (year $\times$ firm $)^{-1}$, we get $X^{*}=25$ firms, for $\alpha^{*}=50$ Year $^{-1}, \beta^{*}=4$ (year of firms $)^{-1}, \gamma=3 / 2(\text { year } \times \text { firms })^{-1}$, we get $X^{*}=50$ firms, where in $\lim _{\gamma \rightarrow 2} X^{*}(\gamma)=\infty$.

\section{Literature review and problem statement}

Analysis of the latest research and publications shows that within the framework of the concept of "birth - death", originating in population dynamics, in [2] the concept of cooperation is considered and those interpretations that correspond to the paradigm of population dynamics are singled out. At present, a much smaller amount of knowledge is devoted to the concept of cooperation, in comparison with the concept of competition. The fact is that the process of competition was traditionally based on the research of market processes. This situation has not changed significantly in the last quarter of a century. In order to substantiate the above, the statement was conducted in the IAEA database "INIS", containing more than 2 million abstracts of works on the environmental-energy and environmental-economic issues, which showed the advantage of work on the modeling of competitive interactions in the economy in comparison with similar cooperation works in the ratio of $3: 1$.

In [3] the economic concepts of competition are analyzed, and their connections with the principles of population dynamics are revealed. It is shown that the subject area of modeling of competitive interactions is much more developed than cooperative ones, and in the stream of domestic theses a negligible part of the research is connected with nonlinear models in the economy. The selection of methods for the qualitative theory of dynamical systems as the most appropriate to the classical behavioral approach in studying the processes of competitive-cooperative interactions is substantiated. 
Further in [4] the model of competitive interactions in the general labor and capital markets of an arbitrary number of countries is considered. Such model can be taken into account when concluding agreements on cooperation between countries. The analogy of the considered relations are contractual interactions offered by the countries of North America on the example of NAFTA, in the conditions of which citizens with Canadian and Mexican citizenship have the right to visa-free work and business in the USA. Detailed cases of this model for one country are analyzed in detail. Equilibrium states are found in these cases, their stability is analyzed, and saddle-type bifurcations are investigated.

In [5] the model of interaction of a labor and vacant jobs in a labor market is considered. A detailed qualitative analysis of this model has been performed, and bifurcation features that lead to dangerous (unstable) labor market functioning regimes have been sufficiently studied. The conditions for the existence of a stable state of the dynamics of the unemployed population and vacant jobs are found. Thus, a toolkit has been developed that allows to predict the equilibrium levels of the unemployed population and vacant jobs. The papers [2-5] consider the conceptual framework that will solve the problems of macroeconomic instability, but in the context of solving problems at the micro- and meso-levels and Ukraine's transition to the model of innovative development.

Let's define the range of previously unresolved parts of the general problem. In the light of Ukraine's likely transition to the model of innovative development, the transition from the previously considered mathematical models with lumped parameters to mathematical models with distributed parameters will be of great importance. This follows from the fact that technopolis can be represented in the form of regional innovation systems with distributed parameters (characteristics). Such system may include technology parks, scientific parks, innovation funds, venture and consulting firms, higher education institutions, business schools, service infrastructure, etc. Identify the main types of development of territorial systems in which diffusion of innovation and the modern role of "semi-periphery" are realized, which is regarded as an intermediate link between the "center" and "periphery" as a stabilizing element in the world division of labor.

\section{The aim and objectives of research}

The main aim of this work is to analyze the mathematical model of diffusion of innovations (1) with lumped parameters and their development in a mathematical model with distributed parameters. In the basis of constructing dynamic models with distributed parameters, it is expedient to consider the kinetic-diffusion model of innovations. For this aim, the following tasks are set:

1. Prove that the cooperative model of the dynamics of innovatively oriented firms is globally stable at a non-trivial equilibrium point. Carry out numerous experiments and show the economic interpretation of the attached results.

2. The diffusion model of innovation, which allows to determine the equilibrium levels of the number of innovatively oriented firms (producers, distributors and consumers) develops to a model with distributed parameters.

3. Identify the main types of development of territorial systems, within which diffusion of innovation and the modern role of "semi-periphery" are realized, which is regarded as an intermediate link between the "center" and "periphery" as a stabilizing element in the world division of labor.

\section{Materials and methods of research}

The methodological basis of this research is the scientific works of domestic [1-6] and foreign scientists [7-18] in the field of modeling of socio-economic systems and economic dynamics. The tools of system analysis, simulation modeling, socio-economic forecasting, based on the provisions of economic theory, the theory of nonlinear dynamical systems and decision theory are used in the study. The economic concepts of competition [3] and cooperation [2] are analyzed, and their 
connections with the principles of population dynamics $[1,4-14,16]$ are revealed. The existing classifications of the methods of modeling socio-economic systems in the context of competitive-cooperative interactions are generalized, and a review of existing methods of such modeling is provided. The selection of methods for the qualitative theory of dynamical systems as the most appropriate to the classical behavioral approach in studying the processes of competitive-cooperative interactions is substantiated.

\section{Research results}

In the basis of constructing dynamic models with distributed parameters, let's propose a diffusion model for innovations. In the framework of the model (3), this indicates that on the right-hand side of this model one must introduce diffuse operators (terms) and to consider a system of partial differential equations:

$$
\left\{\begin{array}{l}
\frac{\partial \mathrm{G}}{\partial \mathrm{t}}=\left[\left(\alpha_{0}-\beta_{0}\right)-\beta_{1} \mathrm{G}\right] \mathrm{G}+\gamma_{12} \mathrm{GN}+\gamma_{13} \mathrm{GP}+\lambda_{1}\left[\frac{\partial^{2} \mathrm{G}}{\partial \mathrm{x}^{2}}+\frac{\partial^{2} \mathrm{G}}{\partial \mathrm{y}^{2}}\right], \\
\frac{\partial \mathrm{N}}{\partial \mathrm{t}}=\left[\left(\tilde{\alpha}_{0}-\tilde{\beta}_{0}\right)-\tilde{\beta}_{1} \mathrm{~N}\right] \mathrm{N}+\gamma_{21} \mathrm{NG}+\gamma_{23} \mathrm{NP}+\lambda_{2}\left[\frac{\partial^{2} \mathrm{~N}}{\partial \mathrm{x}^{2}}+\frac{\partial^{2} \mathrm{~N}}{\partial \mathrm{y}^{2}}\right], \\
\frac{\partial \mathrm{P}}{\partial \mathrm{t}}=\left[\left(\bar{\alpha}_{0}-\bar{\beta}_{0}\right)-\bar{\beta}_{1} \mathrm{P}\right] \mathrm{P}+\gamma_{31} \mathrm{PG}+\gamma_{32} \mathrm{PN}+\lambda_{3}\left[\frac{\partial^{2} \mathrm{P}}{\partial \mathrm{x}^{2}}+\frac{\partial^{2} \mathrm{P}}{\partial \mathrm{y}^{2}}\right],
\end{array}\right.
$$

where $\mathrm{x}, \mathrm{y}-$ the spatial coordinates.

On the basis of the analogy with the problems of heat transfer or impurities, it is well known that in the absence of sources and drains

$$
\left(\alpha_{0}=\tilde{\alpha}_{0}=\bar{\alpha}_{0}=\beta_{0}=\tilde{\beta}_{0}=\bar{\beta}_{0}=\beta_{1}=\tilde{\beta}_{1}=\bar{\beta}_{1}=0, \gamma_{\mathrm{ij}}=0\right)
$$

and zero boundary conditions (at the periphery of the regional innovation system, the absence of innovative structures of all types is specified), a complete degradation of the spatial innovation system occurs $\lim _{t \rightarrow \infty} \mathrm{G}(\mathrm{x}, \mathrm{y}, \zeta, \mathrm{t})=\lim _{\mathrm{t} \rightarrow \infty} \mathrm{N}(\mathrm{x}, \mathrm{y}, \zeta, \mathrm{t})=\lim _{\mathrm{t} \rightarrow \infty} \mathrm{P}(\mathrm{x}, \mathrm{y}, \zeta, \mathrm{t})=0$.

In our case, the presence of terms generated in the dynamical system (8) (at least terms with positive coefficients $\gamma_{\mathrm{ij}}$ ), even if there is a zero boundary condition, can lead to boundaries in complex spatial organizational structures (the process of spatial self-organization). Examples of such models in the area of city formation are given in $[15,16]$. Kinetically diffuse spatial mathematical models of the spread of innovations can be a good implementation of the conceptual provisions laid down in many foreign theories of regional analysis and development.

In the framework of the diffusion approach, in accordance with the above-mentioned types of territorial systems, two independent directions for the study of the dichotomy between central and peripheral structures were formed: a narrower urban one, on which, for example, the concept of growth poles is constructed and the wider regional (regional) underlying many concepts and theories of recent times.

Let's note that the concept of growth poles in different variations was placed in the basis of regional programs of many countries. The creation of various poles and development centers was originally intended to activate economic activity in other peripheral areas. This, for example, is also directed at the existing European regional policy based on the creation of a network of Euroregions (cross-border regions) and investment of funds (from the general budget of the EU) in backward regions, with the aim of pulling them to the level of stronger regions. This regional policy is implemented within the framework of a number of EU programs, for example, within the framework of the INTERREG program. Simultaneously with the concepts of polarized development, interest in concepts and theories explaining the process of constant reproduction of unevenness in the development of countries and regions, as well as the reasons for maintaining 
backwardness, has recently increased. For example, according to "center-periphery" concept, uneven economic growth and the process of spatial polarization inevitably generates disproportions in the socio-economic development between the core and periphery.

The driving force for development and reproduction of the "center-periphery" system of relations, in our opinion and the opinion of other researchers [1], is a constant qualitative transformation of the core through the generation, introduction and diffusion of innovations. Despite the fact that the innovation and information is spreading from the core to the periphery, the main innovation transformation occurs within the core, in addition, the core constantly downloads all kinds of resources from peripheral areas, also strengthens and fixes the differences between them, weakening the periphery. We constantly observe these processes in all countries: the capitals are extracting resources from regional centers, and regional centers are extracting resources from their regions. We also observe processes where the industries that don't correspond to the status of the core as the main generator of scientific and technological progress are gradually being pushed to the periphery. This process, known as the "diffusion of obsolete innovations", plays an important role in the transfer of growth impulses from the center to the periphery, contributing to its development, although thus securing its firm subordination to the center.

The concept of semi-periphery is introduced in the development of the "center-periphery" model $[17,18]$, which is regarded as an intermediate link between the center and the periphery, connects the features of both, is exploited by the core, but exploits the periphery and is a kind of stabilizing element in the world division of labor.

\section{Discussion of research results}

As it is determined, the scientific basis of this research is the scientific works of domestic and foreign scientists and the authors' work in the field of modeling of socio-economic systems based on the provisions of modern economic theory (post-neoclassical synergetic paradigm), the theory of nonlinear dynamical systems and decision theory. This research is a conceptual basis that will solve the problems of macroeconomic instability in the country, but in the context of solving problems at the micro- and meso-levels and Ukraine's transition to the model of innovation development, especially in the leading science-intensive city centers and regions corresponding to them. It is proved that the cooperative model of the dynamics of innovatively oriented firms is globally stable at a nontrivial equilibrium point. Conditions have been found that make it possible to determine the equilibrium levels of the number of innovatively oriented firms. The next step of the research (which is planned in the next works) is the numerical modeling and forecasting of the necessary number of technology parks, scientific parks, innovation funds, venture and consulting firms, higher education institutions, business schools, service infrastructure, etc. to ensure the conditions for economic growth of the country and the region, to solve the problems of employment.

\section{Conclusions}

1. A third-order autonomous dynamic system is proposed that describes the dynamics of producers $(\mathrm{G})$, distributors $(\mathrm{N})$ and consumers $(\mathrm{P})$ of innovations. In general, it can generalize that, unlike the models of competitive interactions for which modes of rapid suppression of one socio-economic object by another (saddle points) are observed in nontrivial points, the considered cooperative model of the dynamics of innovatively oriented firms is globally stable at a nontrivial equilibrium point. This indicates that, regardless of the initial state of the economic dynamic system, it has a single stable equilibrium state. Thus, it is proved that the cooperative model of the dynamics of innovatively oriented firms globally stable at a nontrivial equilibrium point. The economic interpretation of the quantitative parameters of the model (3) is as follows.

For the first set of parameters $\alpha^{*}=50$ year ${ }^{-1}$ means the initial total rate of birth of innovatively oriented firms (the difference between the initial rates of birth and death of firms) is equal to fifty firms per year in terms of one firm; $\beta^{*}=4$ (year $\times$ firm $)^{-1}$ is the coefficient of internal firm competition for all three classes of firms, indicates that 4 firms are dead in the year in terms of one firm of each class; 
$\gamma=1$ (year $\times$ firm $)^{-1}$ is the coefficient of inter-firm cooperation, indicates the annual growth of firms in the amount of one firm in terms of one firm of each class. With these given parameters, a stable equilibrium number of innovatively oriented firms in each of their classes is obtained in the number of 25 firms (the total number of firms of all classes is $3 \times 25=75$ firms). Further, we see that when the coefficient $\gamma$ is increased by $1.5(\gamma=3 / 2)$ with constant other parameter values, a stable equilibrium number of firms in each class increased by half $\left(\mathrm{X}^{*}=50 \mathrm{firms}\right)$. A further increase in the parameter $\gamma$ leads to a sharp increase in the stable equilibrium value of $\mathrm{X}^{*}$.

2. In the basis of constructing dynamic models with distributed parameters, a model of diffusion of innovations is proposed. In the framework of the model (3), diffuse operators (terms) are introduced in the right-hand side of this model and a system of partial differential equations (8) is considered.

3. In our opinion, there are two main types of territorial systems in which diffusion of innovations is carried out:

1) system of countries and regions of different levels of hierarchy, among which there is always a more developed core (center) and a closely related periphery;

2) hierarchical system of cities as the main centers of innovation also includes more developed centers - generators of scientific and technological progress and the lower-order centers dependent on them. For example, in Ukraine, 5 leading knowledge-based centers-cities have already been formed for a long time: Kiev, Kharkov, Dnipro, Odessa, Lviv and corresponding regions.

From the point of view of our models of dynamic systems, it is easy to see that considered three-chain system can be described using a three-dimensional exploiter-victim model. Diffuse operators can be introduced into this model and it is quite possible that the solution of this model can lead to spatial and temporal periodic structures. To do this, it suffices to recall that in the simplest three-dimensional model, without allowance for diffuse terms, periodic solutions arise. Let's note that the semi-periphery is the most dynamic link in the entire hierarchical system, as a rule, the reorganization of the intermediate space occurs during periods of economic crises. In these periods, obviously, a complex dynamics is observed, up to the presence of deterministic chaos. Thus, to solve the problems of macroeconomic stability in the conditions of Ukraine's transition to the model of innovative development, the transition from the mathematical models with lumped parameters to mathematical models with distributed parameters will be of great importance. This follows from the fact that technopolis can be represented in the form of regional innovation systems with distributed parameters (characteristics). Such system may include technology parks, scientific parks, innovation funds, venture and consulting firms, higher education institutions, business schools, service infrastructure, etc.

\section{References}

[1] Moskovkin, V. M. (1998). Osnovy koncepcii diffuzii innovacij. Biznes Inform, 17-18, 41-48.

[2] Zhuravka, A. V., Moskovkin, V. M., Eleodzho O. (2014). Sutnist procesiv kooperaciyi v socialno-ekonomichnyh systemah. Ekonomika. Upravlinnya. Innovaciyi, 1 (11).

[3] Zhuravka, A. V., Moskovkin, V. M., Eleodzho, O. (2013). Sutnist procesiv konkurenciyi v socialno-ekonomichnyh systemah. Ekonomika. Upravlinnya. Innovaciyi, 1 (9).

[4] Zhuravka, A. V., Timofyeyev, V. O., Okeme Eleodzho. (2015). Modelyuvannya spilnoyi dynamiky VVP ta robochyh miscz. Ekonomika. Upravlinnya. Innovaciyi, 1 (13).

[5] Zhuravka, A. V, Timofyeyev, V. O., Mudashyru Tajo Musbao. (2016). Matematychne modelyuvannya spilnoyi dynamiky robochoyi syly i vilnyh robochyh miscz na rynku praci. Ekonomika. Upravlinnya. Innovaciyi, 2 (17).

[6] Moskovkin, V. M, Zhuravka, A. V. (2003). P'er-Fransua Verhul'st zabytyj pervootkryvatel' zakona logisticheskogo rosta i odin iz osnovatelej ekonomichesko dinamiki. Nauka ta naukoznavstvo, 2, 75-84.

[7] Arrow, K. J., Intriligator, M. D. (1981). Handbook of Mathematical Economics Volume 1. North Holland, Amsterdam, 378. 
[8] Takeuchi, Y., Karmeshu. (1989). Dynamic model of three competing social groups. International Journal of Systems Science, 20 (11), 2125-2137. doi: 10.1080/00207728908910292

[9] Gondolfo, G. (1997). Economic Dynamics. Berlin: Springer-Verlag, 599.

[10] Verhulst, P. F. (1838). Notice sur la loi que la population suit dans son accroissement. Correspondence Mathematique et Physique. Bruxelles, 10, 113-121.

[11] Verhulst, P. F. (1845). Recherches mathematiques sur la loi d'accroissement de la population. Nouveaux Momoires de l'Academie Royale des Sciences et Belles Lettres de Bruxelles, 18, 1-38.

[12] Vollterra, V. (1931). Lecons sur la theorie mathematique de la lutte pour la vie. Paris.

[13] Vollterra, V. (1926). Variazioni e fluttuazioni del numero d'individui in specie animali conviventi. «Mem. Acad. Lincei», 2.

[14] Dos-Santos, E. M. (1997). Evolutionist approach of upstream activities competitiveness of the petroleum industry in a long term perspective/Institute Francais du Petrole, 92 - Rueil-Malmaison (France); Dijon Univ., 21 (France). Faculte des Sciences (Dissertation), 451.

[15] Walter, I. (1999). Financial services strategies in the euro-zone. European Management Journal, 17 (5), 447-465. doi: 10.1016/s0263-2373(99)00031-6

[16] Zang, V. B. (1999). Sinergeticheskaja jekonomika. Vremja i peremeny v nelinejnoj jekonomicheskoj teorii. Moscow: Mir, 336.

[17] Wallerstein, J. (1984). The politic of the world-economy. Paris: Maison de Sci. de l'Homme, 295.

[18] Gricaj, O. V., Ioffe, G. V., Trejvish, A. I. (1991). Centr i periferija v regional'nom razvitii. Moscow: Nauka, 168. 